\title{
The secret life of impact breccias: chondritic phosphate shock textures
}

\author{
CRAig WALTON ${ }^{1 *}$, Helen Williams ${ }^{1}$, OLIVER
} SHORTTLE ${ }^{1,2}$

${ }^{1}$ Department of Earth Sciences, University of Cambridge, Downing Street, Cambridge CB2 3EQ, UK. ${ }^{2}$ Institute of Astronomy, University of Cambridge, Madingley Road, Cambridge, CB3 OHA, UK. (*correspondence: crw59@cam.ac.uk)

Phosphate minerals in chondritic meteorites have been widely used to perform $\mathrm{U}-\mathrm{Pb}$ geochronology $[1,2]$. Complete diffusion of $\mathrm{Pb}$ from a phosphate crystal domain will reset the local U-Pb age e.g., during an impact event. Impact events will also disrupt the textural state of phosphate minerals. Indeed, crystal deformatiom/polymorphism may be responsible for controlling $\mathrm{Pb}$ diffusion at the sub-grain scale [3]. However, mineral textures are rarely considered in the study of phosphate U-Pb ages in shocked chondrites [1 vs. 2].

By a systematic classification of phosphate textures, we find evidence for shock-induced internal heterogeneity in many grains in shocked (S3-6) chondrites (Fig. 1). This should be taken into account during the interpretation of spatially-resolved $\mathrm{U}-\mathrm{Pb}$ isotopic data. We argue that phosphate textures may act as an indicator of local PTt pathways, which, combined with compositional and $\mathrm{U}-\mathrm{Pb}$ age data, should serve to resolve several long-standing debates in chondritic impact geochronology. [1] Yin, Q. et al., 2014. MAPS, 49, 8. [3] Li \& Hsu, 2018, American Mineralogist, 103. pp. 1789-1799. [3] Cernok, A. et al., 2019. LPSC abstract \#2132.
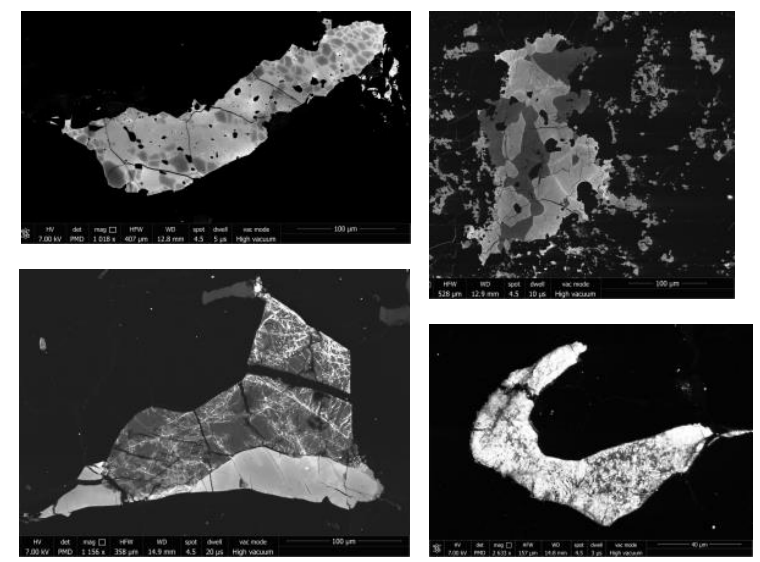

Figure 1: Cathodoluminescence images of shocked phosphate grains. (A) patchy merrrillite (Isoulane, S4), (B) patchy apatite (DaG 978, S3), (C) apatite-tuite polymorphism (Peace River, S6), (D) granularised apatite (Peace River, S6). 